\title{
The Jumbo issue
}

\author{
G. R. Sridhar ${ }^{1}$
}

Published online: 18 September 2015

(C) Research Society for Study of Diabetes in India 2015

Regular readers of the Journal may be surprised by this issue: if not for anything, at least for its size. In a way, it can be considered a metaphor for the burgeoning burden of diabetes in developing countries. Diabetes is rolling over as a juggernaut; research is keeping pace; and it is being documented in diabetes journals worldwide. IJDDC has been no exception in this journey. Over the past few years, the number of accepted articles has far outstripped its slim issues coming out regularly. The long wait appears to be a universal occurrence [1]. To deal with the long list of online first manuscripts, the editorial team and the Society decided to bring them out in print. Future readers may still go online to access them, but a print journal has an obligation to print the accepted articles. Hence this tome; expect a couple more shortly, the latter covering specific themes.

The prevalence of diabetes is high in developing countries and increasing; reports from nationwide studies, both urban and rural, from independent endocrine centers and among specific groups including police personnel have shown a uniform pattern [2-6]. Contributing factors particularly in the northern states include westernization of lifestyle and urban migration [7]. In this issue, a study from Kabul documents the prevalence of diabetes; hypertension was reported to be common as well [8]. Among other Asian countries, treatment patterns and outcomes from Korea are presented in this issue.

Being a silent disease, often undiagnosed, apparently benign until symptomatic, awareness about the condition is important for early identification and lifestyle changes needed

G. R. Sridhar

sridharvizag@gmail.com

1 Endocrine and Diabetes Centre, 15-12-15 Krishnanagar, Visakhapatnam 530002, India for management. Reports have suggested that knowledge improves compliance and reduces complications [9]. Currently, awareness and knowledge are both inadequate in rural as well as urban areas of India [10, 11]. The situation is particularly worrisome in the rural parts of the country. Screening methods such as validated diabetes scores are available, which can be cost-effectively employed along with point of testing methods $[12,13]$. A risk score has been evaluated in the current issue of the Journal.

Rural to urban migration is an ongoing and major contributor to increasing prevalence of obesity and diabetes mellitus [14]. Gender differences in access to medical care exist both in India and other developing countries $[15,16]$. While men had better dietary compliance [15], women were reported to have low self-efficacy and time to take care of their diabetes [16]. In addition, differences exist also among components of metabolic syndrome [17], concentrations of plasma total homocysteine [18], and in peripheral neuropathy [19].

In addition, aging populations face peculiar constraints in the management of non-communicable diseases, as reported in this issue. Diabetes was a substantial burden among the elderly in both urban [20] and rural communities [21]. In addition to psychosocial and economic aspects, the risk of hypoglycemia is an important concern: owing to co-existent renal compromise. One must choose and adjust the dose of antidiabetic medications carefully [22, 23].

Commonly encountered but uncommonly documented associations with diabetes include impaired hearing and periarthritis of the shoulder; these are also presented in the current issue. Diabetes can involve the musculoskeletal system in the form of adhesive capsulitis which causes pain and restricted movement, particularly for external rotation. Frozen shoulder is a more severe form of movement restriction, having a worse outcome [24]. In addition to the pain and discomfort, adhesive capsulitis, in association with limited joint 
mobility and Dupuytren's disease, could co-exist with retinopathy [25]. It may therefore be a marker of diabetic microvascular disease. Common pathogenetic features of angiopathy and minor trauma may contribute, along with biochemical abnormalities such as hypomagnesemia [26].

As reported in this issue, impaired hearing is an often unrecognized condition in diabetes. There have been studies on hearing loss in relation to risk factors such as smoking, central adiposity, and diabetes [27]. Hyperinsulinemia in the prediabetes phase could lead to hearing loss in primate models, with involvement of the cochlea where higher frequency identification is lost [28]. Hypertension, which is common in subjects with geriatric diabetes mellitus [29], can disturb inner ear potassium recycling via natriuretic hormone and a decreased cochlear oxygen partial pressure [30]. This evidence obtained primarily from animal studies must be confirmed in humans, where other confounding conditions exist such as coronary artery disease, dyslipidemia, smoking, and exposure to noise, the latter leading to loss of hearing in the higher frequency range [30, 31].

While sexual dysfunction in men with diabetes is recognized [32], it is less commonly identified in women. The current issue of the Journal carries a study from China. Women with diabetes have higher rates of sexual dysfunction compared to controls [33]. Depression affects all aspects of sexual function including lubrication, desire, arousal, and orgasm [34]. Women with type 1 diabetes had greater sexual dysfunction than those with type 2 diabetes [35]. However, other concomitant conditions such as neurovascular involvement, poor body image perception, and psychosocial factors could also contribute.

Emerging risk factors involving insulin resistance have also been covered: pregnancy-induced hypertension and intimal medial thickness (IMT) as a surrogate for future cardiovascular risk. While polycystic ovary syndrome has been identified as a cardiovascular risk factor [36], further down in the reproductive process, pregnancy-induced hypertension is also considered an insulin resistance state involving inflammatory factors and growth factors [37].

Intimal medial thickening as measured by ultrasound is a non-invasive method to predict coronary artery disease. Indian studies have shown that increased IMT occurred in type 2 diabetes mellitus, as well as in polycystic ovary syndrome, even accounting for age and body mass index [38, 39]. To obtain leads into these possible associations, registries for type 1 diabetes mellitus would be useful, such as the ADCM registry from a Malaysian adult type 2 diabetes in this issue. Regional, national, and global registries, similar to type 1 diabetes mellitus and growth hormone therapy, are possible with electronic medical record networking [40].

Plants have been a perennial favorite in pursuit of their antidiabetic activity. Two papers in the current issue explore these. What is likely to be of greater interest is to characterize plant components using newer omics technology and apply bioinformatics methods to identify nucleotide and amino acid sequences relevant to putative antidiabetic actions, such as insulin-like molecules [41, 42]. Finally, surgical intervention such as sleeve gastrectomy which has been primarily employed in morbid obesity (reported in this issue of the Journal) are making inroads into treatment of type 2 diabetes mellitus. Ongoing studies should throw light on their place in mainstream treatment of diabetes [43].

In dealing with the diabetes juggernaut, it is wistful to think, if only the burgeoning diabetes epidemic worldwide could be contained like the backlog of articles within the pages of journals.

\section{References}

1. Anon. Publishing delays raise hackles. Nature. 2015;523:131.

2. Anjana RM, Pradeepa R, Deepa M. Prevalence of diabetes and prediabetes (impaired fasting glucose and/or impaired glucose tolerance) in urban and rural India: phase I results of the Indian Council of Medical Research-INdia DIABetes (ICMR-INDIAB) study. Diabetologia. 2011;54:3022-7.

3. Sadikot SM, Nigam A, Das S, et al. The burden of diabetes and impaired glucose tolerance in India using the WHO 1999 criteria: prevalence of diabetes in India study (PODIS). Diabetes Res Clin Pract. 2004;66:301-7.

4. Mallik D, Mukhopadhyay DK, Kumar P, Sinhababu A. Hypertension, prehypertension and normotension among police personnel in a district of West Bengal, India. J Assoc Physicians India. 2014;62:12-6.

5. Sridhar GR, Venkata P, Lakshmi G. Time trends in the prevalence of diabetes mellitus : ten year analysis from Southern India (19942004) on 19,072 subjects with diabetes. J Assoc Physicians India. 2010;58:290-4.

6. Gutch M, Razi SM, Kumar S, Gupta KK. Diabetes mellitus: trends in northern India. Indian J Endocrinol Metab. 2014;18:731-4.

7. Saeed KM, Rasooly MH, Brown NJ. Prevalence and predictors of adult hypertension in Kabul, Afghanistan. BMC Public Health. 2014;14:386.

8. Chavan GM, Waghachavare VB, Gore AD, Chavan VM, Dhobale RV, Dhumale GB. Knowledge about diabetes and relationship between compliance to the management among the diabetic patients from rural area of Sangli district, Maharastra, India. J Family Med Prim Care. 2015;4:439-43.

9. Deepa M, Bhansali A, Anjana RM, et al. Knowledge and awareness of diabetes in urban and rural India: the Indian Council of Medical Research India Diabetes Study (Phase 1): Indian Council of Medical Research India Diabetes 4. Indian J Endocrinol Metab. 2014;18:379-85.

10. Kishore J, Kohli C, Gupta N, Kumar N, Sharma PK. Awareness, practices and treatment seeking behavior of type 2 diabetes mellitus patients in Delhi. Ann Med Health Sci Res. 2015;5:266-73.

11. Basu S, Millett C, Vijan S, Hayward RA, Kinra S, Ahuja R, et al. The health system and population health implications of large-scale diabetes screening in India: a microsimulation model of alternative approaches. PLoS Med. 2015;12(5), e1001827.

12. Ritchie GE, Kengne AP, Joshi R, Chow C, Neal B, Patel A, et al. Comparison of near-patient capillary glucose measurement and a risk assessment questionnaire in screening for type 2 diabetes in a high-risk population in rural India. Diabetes Care. 2011;34:44-9. 
13. Ebrahim S, Kinra S, Bowen L, et al. The effect of rural-to-urban migration on obesity and diabetes in India: a cross-sectional study. PLoS Med. 2010;7, e1000268.

14. Sridhar GR, Madhu K, Veena S, Madhavi R, Sangeetha BS, Rani A. Living with diabetes: Indian experience. Diabetes Metab Syndr Clin Res Rev. 2007;1:181-7.

15. Shrestha AD, Kosalram G, Gopichandran V. Gender difference in care of type 2 diabetes. J Nepal Med Assoc. 2013;52:245-50.

16. Srinivas M, Srinivasan V, Mohan MB, Varghese J, Venkataraman J. A study of gender-wise risk association between fatty liver and metabolic syndrome components (Asia-Pacific) criteria in a South Indian urban cohort. Indian J Gastroenterol. 2015;34:38-42.

17. Naik S, Joglekar C, Bhat D, et al. Marked gender difference in plasma total homocysteine concentrations in Indian adults with low vitamin $B_{12}$. Int J Vitam Nutr Res. 2011;81:306-16.

18. Kodali VR, Seshaiah V, Kumar TV. Gender differences in the associated complications among type-II diabetics with peripheral neuropathy. Neurologia. 1990;39:3-7.

19. Bharati DR, Pal R, Rekha R, Yamuna TV, Kar S, Radjou AN. Ageing in Puducherry, South India: an overview of morbidity profile. J Pharm Bioallied Sci. 2011;3:537-42.

20. Radhakrishnan S, Balamurugan S. Prevalence of diabetes and hypertension among geriatric population in a rural community in Tamilnadu. Indian J Med Sci. 2013;67:130-6.

21. Bajwa SJ, Sehgal V, Kalra S, Baruah MP. Management of diabetes mellitus type 2 in the geriatric population: current perspectives. J Pharm Bioallied Sci. 2014;6:151-7.

22. Shastry R, Adhikari P, Kamath A, Chowta M, Ulla S, Pai MR. Do geriatrics require dose titration for antidiabetic agents? J Postgrad Med. 2013;59:271-4.

23. Garcilazo C, Cavallasca JA, Musuruana JL. Shoulder manifestations of diabetes mellitus. Curr Diabetes Rev. 2010;6:224-40.

24. Balci N, Balci MK, Tuzuner S. Shoulder adhesive capsulitis and shoulder range of motion in type II diabetes mellitus: association with diabetic complications. J Diabetes Complicat. 1999;13:135-40.

25. Mavrikakis ME, Sfikakis PP, Kontoyannis SA, Antoniades LG, Kontoyannis DA, Moulopoulou DS. Clinical and laboratory parameters in adult diabetics with and without calcific shoulder periarthritis. Calcif Tissue Int. 1991;49:288-91.

26. Cruickshanks KJ, Nondahl DM, Dalton DS, et al. Smoking, central adiposity, and poor glycemic control increase risk of hearing impairment. J Am Geriatr Soc. 2015;63:918-24.

27. Fowler CG, Chiasson KB, Colman R, Kemnitz JW, Beasley TM, Weindruch RH. Hyperinsulinemia/diabetes, hearing and aging in the University of Wisconsin calorie restriction monkeys. Hear Res. 2015;328:78-86.
28. Pratim DP, Bhaswati S, Nilanjan G, et al. Hypertension and related morbidity among geriatric population of Eastern India. Mater Sociomed. 2012;24:29-33.

29. Przewozny T, Gojska-Grymajto A, Kwarciany M, Gasecki D, Narkiewicz K. Hypertension and cochlear hearing loss. Blood Press. 2015;24:199-205.

30. Lee JS, Choi HG, Jang JH, et al. Analysis of predisposing factors for hearing loss in adults. J Korean Med Sci. 2015;30:1175-82.

31. Sridhar GR. Contribution of psychosocial and physical factors in diabetic sexual dysfunction. Soc Sci Int. 1992;8:1-4.

32. Li F, Wang Y, Xiao L, Lou Q, Fish AF. Frequency, severity and risk factors related to sexual dysfunction in Chinese women with type 2 diabetes. J Diabetes. 2015. doi:10.1111/1753-0407.12335.

33. Elyasi F, Kashi Z, Tasfieh B, Bahar A, Khademloo M. Sexual dysfunction in women with type 2 diabetes mellitus. Iran J Med Sci. 2015;40:206-13.

34. Mazzilli R, Imbrogno N, Elia J, et al. Sexual dysfunction in diabetic women: prevalence and differences in type 1 and type 2 diabetes mellitus. Diabetes Metab Syndr Obes. 2015;8:97-101.

35. Nagamani G, Sundararaman PG, Sridhar GR. Visible signs of insulin resistance: opportunities lost. Int J Diab Dev Countries. 2014;34:177-9.

36. Mastrogiannis DS, Spilioupoulos M, Mulla W, Homko CJ. Insulin resistance: the possible link between gestational diabetes mellitus and hypertensive disorders of pregnancy. Curr Diabetes Rep. 2009;4:296-302.

37. Mohan V, Pradeepa R. Carotid intima-media thickness in type 2 diabetes mellitus. J Assoc Physicians India. 2012;60:9-10.

38. Sundararaman PG, Manomani R, Sridhar GR, Sridhar V, Sundaravalli A, Umachander M. Risk of atherosclerosis in women with polycystic ovary syndrome: a study from South India. Metab Syndr Relat Disord. 2003;1:271-5.

39. Sridhar GR, Rao YSV. Clinical database network. Curr Sci. 2000;79:549-50.

40. Sarada Jyothi K, Srinivas K, Sridhar GR, Subba Rao B, Appa RA. Plant insulin: an in silico approach. Int J Diab Dev Countries. 2010;30:191-3.

41. Jyothi KS, Sridhar GR, Srinivas K, Subba Rao B, Apparao A. In silico pharmaco-gene-informatic identification of insulin-like proteins in plants. Bioinformatics: Concepts, Methodologies, Tools, and Applications. IGI Global, 2013. 948-963

42. Buchwald H, Avidor Y, Braunwald E, et al. Bariatric surgery: a systematic review and meta-analysis. JAMA. 2004;292:1724-37.

43. Mingrone G, Panunzi S, De Gaetano A, et al. Bariatric surgery versus conventional medical therapy for type 2 diabetes. N Engl J Med. 2012;366:1577-85. 